\title{
Three Main Activities of the Department of Education of the Polish Space Agency for 2019-2020.
}

\author{
Sławomir Nichczyński \\ Polish Space Agency \\ Department of Education, POLSA \\ Gdańsk, Poland \\ Slawomir.Nichczynski@polsa.gov.pl
}

\author{
Przemysław Rudź \\ Polish Space Agency \\ Department of Education, POLSA \\ Gdańsk, Poland \\ Przemyslaw.Rudz@polsa.gov.pl
}

\author{
Marek Moszyński \\ Polish Space Agency \\ POLSA \\ Gdańsk, Poland \\ Marek.Moszynski@polsa.gov.pl
}

\section{INTRODUCTION}

Department of Education is one of the sixth departments in organizational structure of Polish Space Agency (POLSA) that was established by the Act of 26 September 2014. In general, the task of the agency is to support the Polish space entrepreneurs by combining the world of business and science. Additionally, the agency should support entrepreneurs in obtaining funds from the European Space Agency (ESA). An important aspect of the Agency's activity is to promote the development of satellite technology that can be used in everyday life, including communication, navigation, environmental monitoring and weather forecasting.

The Polish space sector has developed dynamically in recent years. This shows a need for dedicated education of human resources. On the other hand, further development of the sector depends on a ambitioned projects and programs implemented by the Polish government. This need raise with the level of public awareness associated with the impact of the space sector on the lives of every citizen. That is why the one of the important goals is also gaining public acceptation for the implementation of ambitious space-related projects in Poland.

To achieve both goals: building human resources and raising awareness related to the space sector, a number of education and training initiatives were defined as part of the proposal of National Space Program for 2019-2021. This initiatives covered all levels of education to reach the wide audience on the one hand, and focus on persons who could relate their future with the space sector on the other.
The mentioned tasks will be managed mainly by Department of Education of the Polish Space Agency. The department's employees are experts and specialists in the field of education covering different satellite and space technologies in particular space and earth observation, applications of global navigation systems and satellite telecommunications. POLSA education activities are also related to Polish Space Strategy established by the Act of Law in 2017. One of the goals of this act is also promoting the knowledge on the role of space technology for modern society and building human resources for development of space sector in Poland.

There are three programmes that among several activities of Department of Education as planned for 2019 and 2020 deserves for special attention namely: building the framework for school astronomical observatories, designing the tutorials for astronautics classes and establishing educational programme for increasing the awareness on air quality. The short description of them will be presented in the following sections.

\section{SCHOOL ASTRONOMICAL OBSERVATORIES}

At the level of primary and secondary education, there is a tendency that many young people try to avoid the science. They consider it is difficult or boring. As part of higher education, however, the demand for mathematics, technical and natural science graduates is still growing. Traditional teaching methods and conventional assimilation of theoretical knowledge are not conducive to growing interest in interesting, though often difficult, physical and mathematical 
issues, and sometimes even discourage them. The alternative is the empirical learning, encountering difficult issues on the plane of direct sensations, visual observations and innovation. This approach has a chance to win more supporters among the younger generation, which is great important in the perspective of supplying the fields of study related to astronomy, satellite technologies and the space industry implemented at universities and technical colleges. Education in a dynamically developing field guarantees a perfect start into adult life, interesting work and implementation of ambitious goals and projects.

Astronomy is a science that combines many elements characteristic of exact, natural and humanistic sciences. Recent years have shown the incessantly faster progress of astronomical research, the growing interest of the media in informing about further achievements of astronautics and satellite techniques, successful space probe missions, or subsequent discoveries in remote corners of the Universe. These are issues that feed the imagination not only of young people, but generally of all people interested in the world, regardless of social status, occupation and age. Astronomy contributes to intellectual development, raising the level of awareness of the world around us and satisfying innate human curiosity. It has a fundamental, though not direct, influence on many areas of human life.

A properly conducted and used astronomical observatory can play a special role in the overall educational and pedagogical activity of the school. In terms of the long-term effects of the facility's functioning, they come to the fore, among others:

- Improving the quality of teaching.

- Finding talented students and supporting their development.

- Dissemination of knowledge about astronomy among children, adolescents and adults.

- Popularizing astronomical observations and research due to the use of innovative technologies.

- Increased interest in exact and natural sciences.

- Learning English in astronomical, technical and IT terminology.

- Preventing pathologies by organizing alternative forms of spending time.

- Popularizing the use of information and communication techniques to acquire and expand knowledge.

- Raising the winners of subject competitions and olympiads.

- Counteracting exclusion due to material conditions and place of residence.

- Increasing the attractiveness and competitiveness of the school in the context of using its pedagogical and educational potential.

\section{FUTURE SPACE PROJECT}

One of the most important activities for the astronomical observatory to become a permanent element of the school's current educational activity is to conduct lessons using its potential. These lessons, based on the current core curriculum, will undoubtedly stand out from the rest, and with their specificity will certainly attract a lot of interest. To meet these issues, POLSA in cooperation with the Nicolaus Copernicus University in Torun is preparing a set of several dozen scenarios of full-scale astronomy classes developed by the didactic specialist of this subject. They can be used directly as part of the astronomical classes, as well as during geography, physics, nature, computer science and other lessons throughout the school year. They can be freely modified by the teacher and thus adapted to individual needs. The POLSA Department of Education expresses its willingness and readiness to create a publicly available script database, and thus complete new scenarios other than those listed there. POLSA is also extremely interested in suggestions for other than described possibilities of using the astronomical observatory scripts in education activities with talented youth.

\section{SCHOOL PROGRAMME AIMED FOR INCREASING AWARENESS ON AIR QUALITY}

Inspired by this year Living Planet Symposium that was organized by ESA Centre for Earth Observation (ESRIN) in Milan and especially the presentation of its Air Quality Platform (https://lps19airquality.esa.int/), Polish Space Agency representatives in networking conversations with ESRIN representatives agreed to conduct the programme aimed for increasing awareness on air quality in Poland. The programme will be dedicated especially to young enthusiast, who - by using dedicated starter-kit style device - could register and analyse contents of several components of the air. The device could be easily mounted on an electronic testing board using miniature sensors that could be plugged to popular embedded open source hardware microcontrollers with dedicated firmware.

The first such devices was gifted to POLSA by ESRIN and measures several components of the air including temperature, humidity, particulate matters PM2.5 and PM10, nitrogen oxide $\mathrm{NO}_{2}$, ammonia $\mathrm{NH}_{3}$, carbon dioxide $\mathrm{CO}_{2}$ and carbon monoxide CO. This device runs continuously at the Polish Space Agency headquarters in Gdańsk as the demo for visitors. At the same time the prototype of miniaturized version was developed in Education Department of POLSA that uses the same sensors as in ESA version. The miniaturization was achieved by using of NodeMCU compatible device with esp8266 microchip, which nowadays is very popular among enthusiast of Internet of Things (IoT). This device allows for establishing a WiFi connection to the Internet hot spots and at the same time allows for managing the measurements of all data sequences coming from sensors. As in the original ESA version the whole platform is equipped with four sensors measuring several air parameters like temperature and humidity, PM2.5 and PM10, $\mathrm{CO}_{2}, \mathrm{NO}_{2}, \mathrm{NH}_{3}$ and $\mathrm{CO}$. Fifth additional sensor namely GNSS receiver is 
dedicated not only to automatic extraction of device location but also for measuring of the track of a potential survey that may be organized by teachers for a group of youngsters and also for instructing on the role of all GNSS systems by observing dynamic sky view display of navigational satellites.

The crucial element of presented programme is also the software. ESRIN and POLSA agreed that variety possible hardware and software solutions must be compatible with server side platform established by ESA. In this way there is a future perspective of building the network of devices with insitu data that could be used for verification of data coming from instruments located on satellite platforms.

The prototype version developed in POLSA will be also equipped with dedicated software that runs on mobile devices from which the miniaturized version could be powered. This aspect is especially important when young people on excursion will be hiking outside the regions of network availability.

The programme as being prepared by POLSA could be thought as a national version of pilot programme that - at the same time - is further developed by ESA in its education directorate. High level representative of ESRIN and POLSA agreed to do its best at this very early moment of air quality platform development to spread the knowledge on importance of air quality awareness in our future society.

\section{SUMMARY}

It is necessary to establish the directions for future human resources training for the needs of the space sector. Due to their interdisciplinary nature, specialists in many fields find employment in creating new space technologies, including graduates of such fields as electronics, automation, computer science, mechanics, physics, navigation or even geography. Today, the strength of Polish space personnel is determined by solid education, primarily in the field of basic technical sciences. It is advisable that these specialists, in addition to knowledge in their fields, also acquire knowledge in the field of space applications. The most desirable form of such education seems to be graduate and postgraduate studies specializing in space and satellite engineering. That is why in 2016 Polish Space Agency headquatered in Gdańsk in cooperation with three Pomeranian universities namely Gdańsk University of Technology, Gdynia Marine University and Polish Naval Academy initiated the graduate studies on Space and Satellite Technology. Due to further needs coming from requirements from the sector Curriculum Board of this studies at the moment of writing decided to join University of Gdańsk as the forth pillar of this initiative. 